\title{
Potential of Tithonia diversifolia Chimato Composts in Enhancing Soil Carbon Sequestration
}

\author{
Angstone Noel J. Thembachako MLANGENI ${ }^{1}$ \& Sosten Staphael CHIOTHA ${ }^{2}$ \\ ${ }^{1}$ Basics Studies Programme, NR Department, Natural Resources College (of Malawi), Malawi \\ ${ }^{2}$ Leadership for Environment and Development (LEAD), Chancellor College, University of Malawi, Malawi \\ Correspondence: Angstone Noel J. Thembachako Mlangeni, Natural Resources College (NRC), LILONGWE, \\ Box 143, Malawi. Tel: 265-888-301-288. E-mail: anjtmlangeni@yahoo.com
}

Received: July 6, 2013 Accepted: July 23, 2013 Online Published: September 3, 2013

doi:10.5539/enrr.v3n4p58 URL: http://dx.doi.org/10.5539/enrr.v3n4p58

\begin{abstract}
Composts have different potentials of sequestering carbon into underground soils. The present study assessed soil carbon sequestration potential of Tithonia diversifolia chimato composts (CC). CC was made by blending Tithonia diversifolia with maize stalks (Td/MS) as follows: 0:100, 20:80, 50:50, 60:40, 80:20 and 100:0. Soil treatments pots were arranged in fully randomized design in which a homogeneous mixture of $1.0 \mathrm{~kg}$ of $\mathrm{CC}$ and $4 \mathrm{~kg}$ of soil was placed in pots. 3 maize seeds were planted per pot and standard agronomical practices were followed till harvesting. Soil organic carbon was determined using standard methods before and after each cropping season. Maximum soil carbon retention was observed in treatments supplemented with chimato composts prepared using Td/MS ratios of 50:50 (89.1\%) and 60:40 (92.3\%) compared to those 0:100 (20\%), 20:80 (23.2\%) and 40:60 (10.9\%) which experienced greatest soil organic carbon loss. Significant positive correlation was observed $(\mathrm{r}=0.996 ; \mathrm{P}<0.05)$ between initial $T$. diversifolia used in making chimato composts and soil organic carbon retention wheras significant negative correlation was observed $(\mathrm{r}=0.983)$ between the same with soil organic carbon losses. The observation is attributable to high levels of maturity and stability of $\mathrm{CC}$ prepared with $\mathrm{Td} / \mathrm{MS}=50: 50$ and $\mathrm{Td} / \mathrm{MS}=60: 40$ such that relatively significant stable $\mathrm{C}$ was being oxidized and decomposed to meet microbial and plant $\mathrm{N}$ requirements. Considerable nitrogen loss was observed in treatments with chimato composts prepared using Td/MS $=100: 0$ (58.9\%) and Td/MS $=80: 20(47.7 \%)$ and maximum nitrogen was retained in supplemented with chimato composts prepared using Td/MS $=50: 50(59.1 \%)$ and $\mathrm{Td} / \mathrm{MS}=60: 40(42.3 \%)$. The results suggest $\mathrm{CC}$ with $\mathrm{Td} / \mathrm{MS} \geq 50: 50$ and $\mathrm{Td} / \mathrm{MS} \leq 60: 50$ have great potential of combating climate change through sequestration of huge quantities of carbon into underground soil.
\end{abstract}

Keywords: maize stalks, carbon retention, carbon losses, soil organic carbon, carbon sequestration

\section{Introduction}

Agricultural practices have made significant contribution to total greenhouse gas (about 15.2\%) emissions by letting free soil carbon into the atmosphere, a phenomenon that has consequently made significant effects on climate change (Gill et al., 2012). A number of strategies have been suggested and implemented to mitigate the impacts of climate in different societies and communities. Such strategies include forestation, reforestation, and avoidance of deforestation, conservation agriculture, organic farming and use of compost. Use of compost is an agricultural practice that has great potential of delivering long-term agronomic benefits such as, improving soil fertility, increasing soil water retention and improving soil $\mathrm{pH}$, that enhances increased agricultural production as well as provides fastest means of sequestrating carbon into soil (Biala, 2011; Gill et al., 2012) among others. Ministry of Agriculture and Food Security in Malawi is advancing and encouraging farmers to make and use chimato composts to improve soil fertility in order to increase agricultural production. Chimato composting technology is a pro-poor composting strategy that enhances fast feedstock decomposition under aerobic conditions and significantly improve nitrogen content of resultant composts when recommended blending composition of ingredients are used (Mlangeni, 2013; Nalivata, 2007). Blending composition of Tithonia diversifolia with maize stalks (TD:MS) greater than 40\% has been suggested by Mlangeni (2013) to significantly improve quality of feedstock in compost pile as well as that of the final product (chimato composts) whereas those produced using maize stalks and grass only, organic resource of poor quality, yield immature and poor quality composts) (C:N ratios is large (C/N > 38:1)) (Olabode et al., 2007; WERL, 2005; Mlangeni, 2013). 
Specifically, chimato composts made by blending Tithonia diversifolia (T. diversifolia) with maize stalks in the ratio $\mathrm{Td} / \mathrm{MS}=50 / 50(\mathrm{v} / \mathrm{v})$ and $\mathrm{Td} / \mathrm{MS}=60 / 40($ for both $\mathrm{w} / \mathrm{w}$ and $\mathrm{v} / \mathrm{v})$ produce high quality composts - nitrogen content reaches as high as $2.37 \%$ and $\mathrm{C} / \mathrm{N}$ ratio reaches as low as 12:1 (Mlangeni, 2013). Chimato composts produced using TD:MS $>40 \%$ is also reported to possess large values $\mathrm{pH}(\mathrm{pH}>8.0)$, low $\mathrm{C} / \mathrm{N}$ ratio $(\mathrm{C} / \mathrm{N}<20)$ and high nitrogen content $(\mathrm{N} \geq 1.67 \%$ ) (Mlangeni, 2013). However, most household farmers produce chimato composts using mostly these maize stalks and grass which yield immature composts. Such chimato composts are reported to be well matured and stable (Biala, 2011; Gill et al., 2012); their compost ingredients provide compost piles with optimum aeration and moisture that enhance optimum aerobic decomposition (Mlangeni, 2013; WSU, 2010). It is reported that carbon atoms supplied alongside well matured composts stay longer in the soil (Biala, 2011) because carbon atoms in well matured composts is more stable whereas carbon atoms supplied alongside immature composts continues to degrade uncontrollably in the soil and emit enormous carbon dioxide, methane and nitrous oxide (Biala, 2011; CCQC, 2001). Microbes actively continue to degrade the carbon in the soil using the limited available nitrogen thereby depleting soil carbon, nitrogen and nitrogen (Gill et al, 2012; USCC, 2008). Thus stable carbon atoms supplied alongside well matured composts do not compete with plants for nitrogen or oxygen in the soil (CCQC, 2001; Wu et al., 2000). In addition, underground carbon is reported to be also more stable than surface carbon; hence, carbon atoms ploughed into soil experience minimal degradation. Thus, application of mature composts has potential of locking up carbon and nitrogen in soil. Compost application into agricultural fields effectively diverts emissions from the atmosphere and converts and store the carbon or nitrogen in organic form in underground soils for a long time (Francou et al., 2008; GMWDA, 2009). Significant amount of nitrous oxide is produced when nitrogen biochemical transform in soil mainly through nitrification/denitrification processes. Production of methane has great global warming potential of about 23 times worse than carbon dioxide whereas nitrous oxide is about 296 times worse than carbon dioxide (USCC, 2008; Biala, 2011; Gill et al., 2012). Therefore, there is a need to make significant attempts to reduce production of methane and nitrous oxide alongside carbon dioxide by increasing quantity of carbon atoms retained in soil as well as minimizing quantity of soil carbon losses thereby significantly enhancing soil carbon sequestration. The study was carried to assess the extent chimato composts produced using varied blending ratios of $T$. diversifolia with maize stalks sequestrate carbon into underground soils.

\section{Materials and Methods}

\subsection{Experimental Set up and Treatments}

Seven standard composts $\mathrm{Td} 0, \mathrm{Td} 20, \mathrm{Td} 40, \mathrm{Td} 60, \mathrm{Td} 80$ and $\mathrm{Td} 100$ were made using $T$. diversifolia and maize stalks, blended in the ratios (Td/MS) of 0:100, 20:80, 50:50, 60:40, 80:20 and 100:0 respectively. Both ingredients used in compost pile were chopped into pieces ranging from $5.0 \mathrm{~cm}$ to $10.0 \mathrm{~cm}$ before being composted under a roofed shed. Similarly, seven soil treatments were arranged in a fully randomized design in which a homogeneous mixture of $1.0 \mathrm{~kg}$ of chimato composts and $4 \mathrm{~kg}$ of soil, whose initial carbon content and $\mathrm{pH}$ were low $0.89 \%$ and $\mathrm{pH}(\mathrm{pH}<6)$ respectively, were placed in plastic pots with an inside diameter of $20 \mathrm{~cm}$ and consisted of three replicates. The soil used in the study was collected from a depth of 0-15 $\mathrm{cm}$ at Msundwe area located at $13^{\circ} 31^{\prime} 9.43^{\prime \prime}$ and $+33^{\circ} 57^{\prime} 57.79^{\prime \prime}$ in Lilongwe district, Malawi. Chimato compost supplementation treatments were as follows: - (i) Soil supplemented with Td0; (ii) Soil supplemented with Td20; (iii) Soil supplemented with Td50; (iv) soil supplemented with Td60; (v) Soil supplemented with Td80; (vi) Soil supplemented with Td100; (vii) and Soil supplemented with no compost (control). Four viable maize seeds were planted in each pot. The control pot consisted of $5 \mathrm{~kg}$ soil mass of homogenized soil.

\subsection{Soil Analysis}

Homogenized mixture of soil sample from each treatment were analyzed TKN and organic carbon using the Kjeldahl apparatus (Jeffery et al., 1989) immediately after compost supplementation and after harvest and for $\mathrm{pH}$ using $827 \mathrm{pH}$ lab Metrohm electrode.

\subsection{Data Analysis}

The data was analyzed using SPSS (SPSS 17) computer package. Analysis of variance was done to compare and determine level of variation of TKN, total organic carbon, carbon retention, and carbon losses in soil. Significant differences were determined at $\mathrm{P} \leq 0.05$.

\section{Results and Discussion}

\subsection{Effect of T. diversifolia Chimato Composts on Total Soil Organic Carbon}

Results showed significant increase in soil organic carbon, SOC, in almost all the treatments after cropping season preceding initial compost supplementation except that of the control treatment. As shown in table 1, SOC 
increased by a margin of $29 \%, 44 \%, 61 \%, 140 \%, 143 \%, 79 \%$, and $99 \%$ from an initial SOC content of $0.89 \mathrm{~g}$ in soils supplemented with Td0, Td20, Td40, Td50, Td60, Td80 and Td100 respectively. In the control treatment, SOC content decreased from $0.89 \mathrm{~g}$ to $0.78 \mathrm{~g}$, In other treatments, SOC increased in the following order: Control $<\mathrm{Td} 0<\mathrm{Td} 20<\mathrm{Td} 40<\mathrm{Td} 80<\mathrm{Td} 100<\mathrm{Td} 50<\mathrm{Td} 60$.

Table 1. Carbon variation in supplemented soils over two years (in $100 \mathrm{~g}$ soil)

\begin{tabular}{|c|c|c|c|c|c|c|c|}
\hline $\begin{array}{l}\text { Chimato } \\
\text { Compost }\end{array}$ & $\begin{array}{l}\text { Amount of Initial } \\
\text { SOC }(\mathrm{g})\end{array}$ & $\begin{array}{l}\text { Amount of SOC } \\
\text { (g) }\end{array}$ & $\begin{array}{l}\text { Amount of } \mathrm{SOC}^{\mathrm{a}} \\
\text { gain }(\mathrm{g})\end{array}$ & $\begin{array}{l}\% \text { of } \mathrm{SOC}^{\mathrm{a}} \\
\text { gain }(\%)\end{array}$ & $\begin{array}{l}\text { Amount of } \mathrm{SOC}^{\mathrm{b}} \\
(\mathrm{g})\end{array}$ & $\begin{array}{l}\text { Amount of } \mathrm{SOC}^{\mathrm{b}} \\
\text { lost }(\mathrm{g})\end{array}$ & $\begin{array}{l}\% \text { of } \mathrm{SOC}^{\mathrm{b}} \\
\text { lost }(\%)\end{array}$ \\
\hline Td0 & $0.89 \pm 0.03$ & $1.15 \pm 0.01$ & $0.26 \pm 0.04$ & 29 & $0.64 \pm 0.03$ & $0.51 \pm 0.03$ & 45 \\
\hline $\mathrm{Td} 20$ & $0.89 \pm 0.03$ & $1.28 \pm 0.01$ & $0.39 \pm 0.04$ & 44 & $0.59 \pm 0.03$ & $0.69 \pm 0.03$ & 54 \\
\hline $\mathrm{Td} 40$ & $0.89 \pm 0.03$ & $1.43 \pm 0.03$ & $0.54 \pm 0.05$ & 61 & $0.86 \pm 0.02$ & $0.57 \pm 0.03$ & 40 \\
\hline Td50 & $0.89 \pm 0.03$ & $2.14 \pm 0.03$ & $1.25 \pm 0.10$ & 140 & $1.82 \pm 0.02$ & $0.32 \pm 0.03$ & 15 \\
\hline Td60 & $0.89 \pm 0.03$ & $2.16 \pm 0.03$ & $1.27 \pm 0.10$ & 143 & $1.95 \pm 0.02$ & $0.21 \pm 0.03$ & 10 \\
\hline $\mathrm{Td} 80$ & $0.89 \pm 0.03$ & $1.59 \pm 0.02$ & $0.70 \pm 0.05$ & 79 & $1.44 \pm 0.02$ & $0.15 \pm 0.03$ & 9 \\
\hline $\mathrm{Td} 100$ & $0.89 \pm 0.03$ & $1.77 \pm 0.01$ & $0.88 \pm 0.05$ & 99 & $1.63 \pm 0.02$ & $0.14 \pm 0.03$ & 8 \\
\hline control & $0.89 \pm 0.03$ & $0.78 \pm 0.02$ & $-0.11 \pm 0.03$ & -12 & $0.70 \pm 0.02$ & $0.08 \pm 0.03$ & 11 \\
\hline
\end{tabular}

$\mathrm{a}=$ after 1st (Year) cropping season.

$\mathrm{b}=$ after 2nd (Year) cropping season.

The results indicated that supplementation of chimato composts with $\mathrm{Td} / \mathrm{MS} \leq \mathrm{Td} 40$ significantly increased quantity of Carbon atoms in the soil during the initial cropping season. Generally, the observations showed that chimato compost supplementation positively impacted SOC content. However, SOC in the control treatment decreased from $0.89 \mathrm{~g}$ to $0.78 \mathrm{~g}$ during the same cropping season indicating a negative increase of $-12 \%$. Minimal increments were observed in $\mathrm{Td} 0$ and $\mathrm{Td} 20$ treatments (Table 1) which were supplemented with chimato composts made using large quantities of maize stalks. The observations indicated that different proportions of $T$. diversifolia used in making composts influenced carbon retentions and loss in soils differently. Chimato composts Td60 made using $T$. diversifolia and maize stalks blending ratios of 60:40 influenced greatest increase of SOC of $143 \%$ followed by Td50 that influenced $140 \%$ increase of SOC during the first cropping season. It was also observed that treatments $\mathrm{Td} 0, \mathrm{Td} 20$ and $\mathrm{Td} 40$, supplemented with chimato compost that possessed greatest $\mathrm{C}: \mathrm{N}$ ratios $(\mathrm{C}: \mathrm{N}=33: 1,28: 1$ and 24:1) (Mlangeni 2013) yielded least SOC after first cropping, which did not match the initial composts' carbon content (EPA, 2008). This observation is attributable to rapid uncontrolled carbon oxidation and carbon degradation of immature and unstable components of chimato composts Td0, Td20 and Td40 supplemented in the treatments. The large SOC increase observed in Td50 and Td60 treatments can be explained by both initial quantities of carbon atoms supplemented into the soils and stability of chimato composts Td50 and Td60. Chimato composts Td50 and Td60 did not only supply the soil with greatest quantities of carbon atoms which increased SOC content but also supplied the soils with most stable carbon fractions that resisted significant rapid decomposition since well matured composts possess these in great numbers.

Despite supplying Td80 and Td100 treatments with chimato composts that possessed low quantities of carbon as evidenced by low $\mathrm{C}: \mathrm{N}$ ratios (C:N ratio 11:1 and 12:1 respectively), the treatments relatively showed $79 \%$ and $99 \%$ increase in SOC. Total SOC in Td80 and Td100 treatments were lower than that of Td50 and Td60 treatments. The observation can be explained by stability and quantity of initial carbon in Td80 and Td100 treatments. Even though carbon fractions were stable in chimato composts $\mathrm{Td} 80$ and $\mathrm{Td} 100$, the composts possessed low initial carbon content hence the low observed carbon atoms in Td80 and Td100 treatments (Biala, 2011; Francou et al., 2008; GMWDA, 2009). Since pH (>8.3) values of composts suggest occurrence of $\mathrm{CO}_{3}{ }^{2-}$ precursors to $\mathrm{pH}$, high $\mathrm{pH}$ values of $\mathrm{Td} 80$ and $\mathrm{Td} 100$ treatments could be attributed to presence of $\mathrm{CO}_{3}{ }^{2-}$ that probably formed either calcium carbonate or potassium carbonates or sodium carbonate (CCQC, 2001; Onwueme \& Sinha, 1991) which may take longer to decompose in soils. Therefore, chimato composts in Td80 and Td100 treatments may have had significant influence on the chemistry of soil as well as chemical reactions taking place in the soil which include restricting conversion of carbonates to easily volatized carbon dioxide. Hence, this might have significantly increased carbon retention and decreased carbon losses 


\subsection{Impact of T. diversifolia Chimato Composts on Soil Carbon Retention}

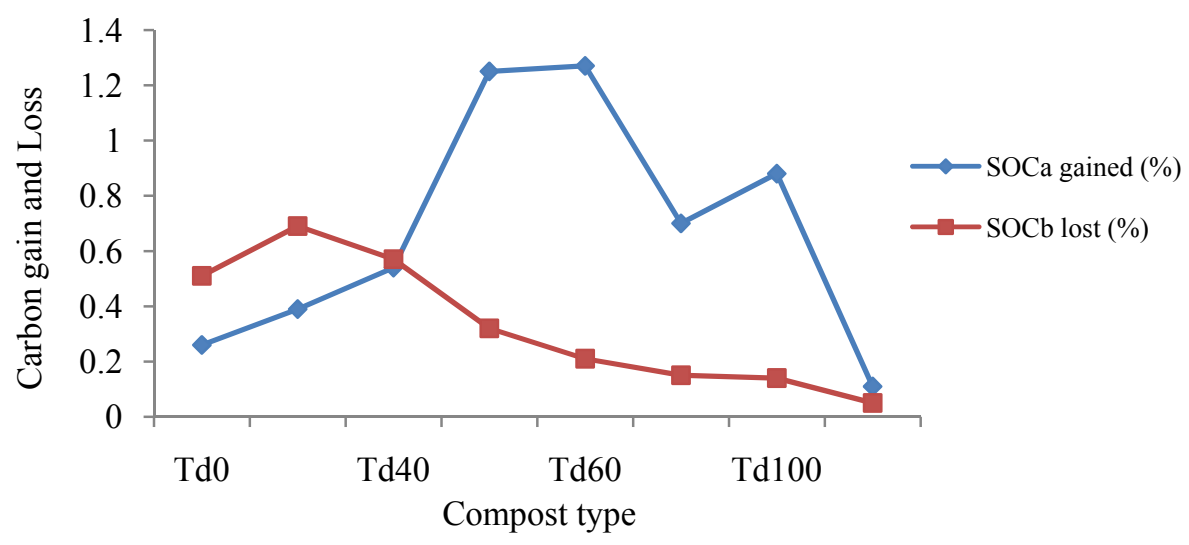

Figure 1. Effect of T. diversifolia chimato composts on soil carbon retention

Carbon retention in each treatment increased in increasing order of $T$. diversifolia used in making chimato composts (up to $60 \% T$. diversifolia). Td60 retained greatest quantity of carbon atoms $(1.27 \mathrm{~g})$ and in other treatments, carbon retention decreased in the following order: $\operatorname{Td} 60>\operatorname{Td} 50>\operatorname{Td} 100>\operatorname{Td} 80>\operatorname{Td} 40>\operatorname{T} 20>$ Td20> control (Figure 1). The observation suggested that within the region of $0-60 \%$ T. diversifolia content in compost piles, $T$. diversifolia indirectly influenced carbon stability in the soil by influencing varied levels of maturity of chimato composts that affected stability carbon atoms. It is suggested that blending compositions of $\mathrm{Td} / \mathrm{MS}$ of 50:50, 60:40, 80:20 and 100:0 in chimato composts Td50, Td60, Td80 and Td100 respectively that influenced optimal aeration and optimal moisture content in chimato composts piles and enhanced thorough maturity of chimato composts (Mlangeni, 2013), further influenced stability of carbon atoms in the soil which further affected the process of $\mathrm{C}$ mineralization. The results are in agreement to the findings of Bernal and others (1998) and reports by EPA (2008) that well matured composts possess large quantities of stable carbon and humic substances that significantly resist further chemical oxidation and microbial degradation. Therefore, it can be argued that chimato composts Td50 and Td60, that indicated highest SOC (1.25 g and $1.27 \mathrm{~g}$ respectively) (Figure 1) during the first cropping season, were most well matured and possessed most stable carbon components implying that they experienced greatest resistance to further degradation (EPA, 2008; Bernal et al, 1998). The results further indicated that chimato composts possessed stable carbon that significantly resisted further chemical oxidation and microbial degradation hence the likely pathway of carbon loss was leaching rather than oxidation and emissions. Therefore, carbon losses in Td80 and Td100 could be attributable to leaching of nutrients as carbonates and other water soluble carboceous compounds hence, the observed high carbon retention. $\mathrm{Td} 0$ and $\mathrm{Td} 20$ treatments retained comparable quantities of soil $\mathrm{C}$-atoms as to those of $\mathrm{Td} 80$ and Td100 treatments during the first cropping seasons (Figure 1). Even though comparable soil C-atoms was retained, it is evident that enormous carbon emissions occurred in $\mathrm{Td} 0$ and $\mathrm{Td} 20$ treatments as a result of decomposition of the large quantity of imported carbon than in $\mathrm{Td} 80$ and $\mathrm{Td} 100$ treatments (Figure 1). By percentage, Td80 and Td100 treatments retained largest proportion ( $79 \%$ and $99 \%$ respectively) whereas $\mathrm{Td} 0$ and $\operatorname{Td} 20$ treatments retained $29 \%$ and $44 \%$ respectively. The observation confirms that $\operatorname{Td} 80$ and $\operatorname{Td} 100$ compost possessed more stable organic carbon atoms that slowly decomposed and chemically resisted further degradation. This process helps reduce emissions by sequestering (locking up) the carbon into underground soil and reduce in $\mathrm{CO}_{2}$ levels in the atmosphere (CAW, 2012; BNYK, 2010). A significant negative correlation was observed between initial T. diversifolia used in making chimato composts and SOC losses $(r=0.996)$. Assuming the SOC loss is translated to carbon emissions; it is clear that during first cropping season, greatest carbon losses occurred in $\operatorname{Td} 0$ then $\mathrm{Td} 20$ followed by $\mathrm{Td} 40$.

\subsection{Impact of T. diversifolia Chimato Composts on SOC Loss}

As shown in Figure 2, during the second cropping season, SOC losses were generally observed reducing in increasing order of quantities of $T$. diversifolia used in making chimato composts supplemented into the soil. Greatest carbon reduction was observed in treatment $\mathrm{Td} 20$ and reduced in the following order: $\operatorname{Td} 20>\operatorname{Td} 0>$ $\operatorname{Td} 40>\operatorname{Td} 50>$ control $>\operatorname{Td} 60=\operatorname{Td} 80>\operatorname{Td} 100$ by percentage. On the other hand, lowest SOC losses were 
observed in the control treatment followed by Td100 treatment, and the losses followed a different pattern which saw Td0 and Td40 swapping positions.

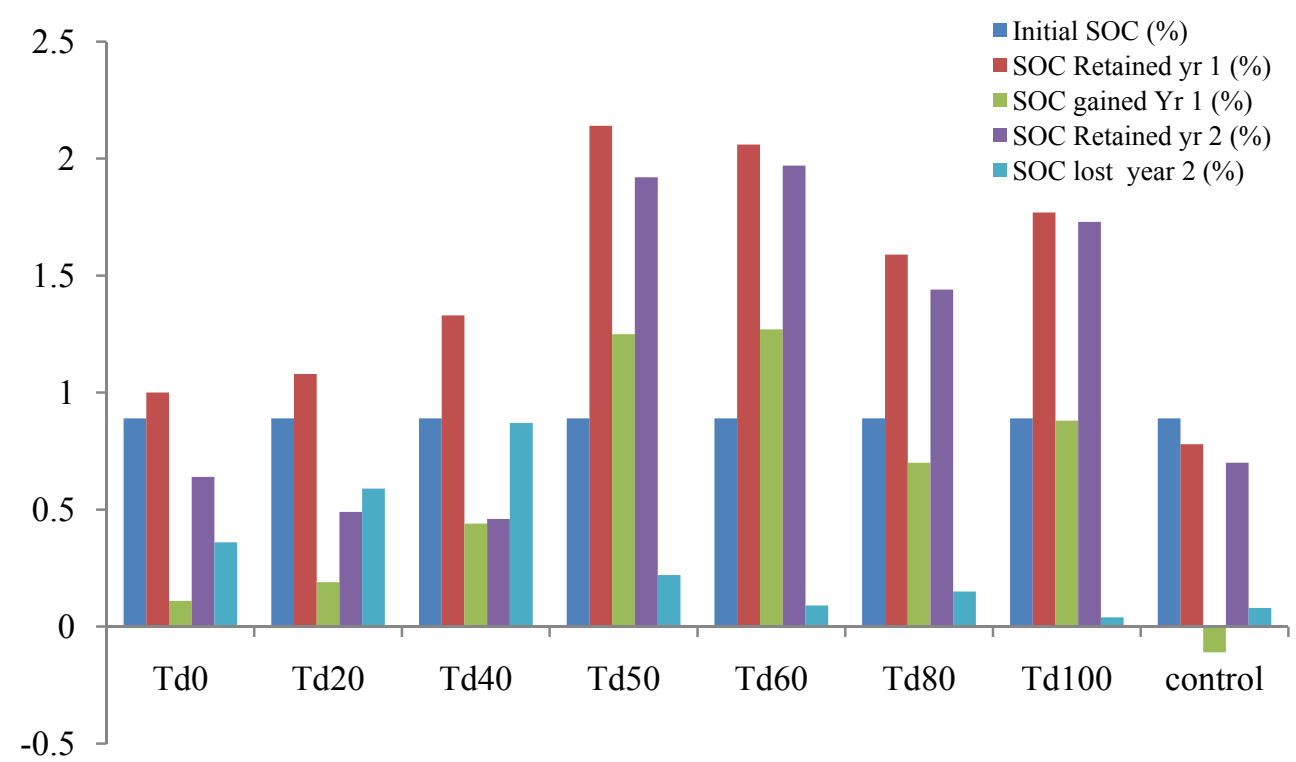

Figure 2. $\mathrm{C}$ atoms retention and carbon loss in various treatments

As observed in Figure 2, carbon losses were in the following order: Td20 $>$ Td40 $>$ Td0 $>$ Td50 $>$ Td60 $>$ Td80 $>$ $\mathrm{Td} 100>$ control. The control treatment lost SOC amounting to $0.11 \mathrm{~g}$ during the first cropping season and 0.08 during the second cropping season representing $12 \%$ and $11 \%$ losses respectively. The observed high values of carbon losses in $\mathrm{Td} 0, \mathrm{Td} 20$ and $\mathrm{Td} 40$ treatments during the second cropping season are attributable to compost's immaturity (since all soil management practices were replicated on each treatment except use of compost) (USCC, 2008; Biddlestone \& Gray, 1987) and high levels of unstableness of carbon atoms in the composts (Francou et al., 2008; GMWDA, 2009). These two factors might have triggered further rapid microbial activities. Thus, instability of carboceous compounds in composts enhanced further chemical oxidation and microbial degradation which released enormous carbon dioxide, methane and nitrous oxides. The minimal values of carbon losses observed in the control treatment are attributed to absence of unstable carbon atoms and/or carboceous compounds. This is because during the subsequent cropping season, the plants used most of the soil nitrogen for biomass building thereby depleting soil nitrogen likely to enhance rapid microbial activities (Francou et al., 2008). In addition, the available stable carbon atoms in the control treatment were in low quantities which experienced minimal anaerobic microbial activities with little or no replacement at all. The observed differences between Td0, Td20, Td40 and the control could also be attributed to absence or minimal availability of nitrogen for microbes to use to degrade the carbon atoms further. Carbon atoms stability seemed to have reached highest possible stability stage. However, Td50, Td60, Td80 and Td100 treatments showed no significant differences in their SOC losses ( $p>0.207, \alpha=0.05$; Wilcoxon). The observation could be explained by carbonates losses and other soluble carbonic compounds. Td80 and Td100 treatments are reported to possess large quantities of carbonates (Mlangeni, 2013b) which were lost as leachate from the pots, hence carbon losses were more pronounced and became at pur with those of Td50 and Td60 treatments. Chimato composts Td50 and Td60 were aerobically more mature (Mlangeni, 2013) and were expected to be more stable and more resistant to further rapid microbial decomposition (Francou et al., 2008) than those of $\mathrm{Td} 0 \mathrm{Td} 20$ and $\mathrm{Td} 40$, since mature composts are characterized by containing large quantities of stable humic substances and table soil carbon remains bound in the soil for long periods of time (GMWDA, 2009). In addition, Td0 and Td20 treatments were also expected to possess relatively largest initial carbon content but indicated lower values of retained carbon; suggesting that greatest carbon losses might have occurred during the first cropping season. The observation is attributed to large quantity of non-compost materials of $\mathrm{Td} 0$ and $\mathrm{Td} 20$ (Mlangeni 2013) that continued to degrade while in soil a process that depleted limited soil and compost nitrogen and carbon further (Biala, 2011; Gill et al, 2012). The observation is also attributed to large $\mathrm{C} / \mathrm{N}$ ratios of $\mathrm{Td} 0$ and $\mathrm{Td} 20$ since carbon mineralization decreases with 
increasing $\mathrm{C} / \mathrm{N}$ ratio (Gill et al, 2012). As a result, significant active and rapid uncontrolled microbial activities and/or oxidation might have continued under anaerobic conditions producing methane, a GHG 72 times more powerful than $\mathrm{CO}_{2}$ (GMWDA, 2009) thereby decreasing soil carbon. Even though, Td0 and Td20 indicated some carbon retention during the initial, it is observed that application of $\operatorname{Td} 0$ and $\operatorname{Td} 20$ would further accelerate production of carbon dioxide and methane in the subsequent years thereby increasing carbon emissions while in the soil.

During the second cropping season, carbon losses were negligible in soils amended with chimato composts made using greater proportion of $T$. diversifolia and maximum carbon retention was observed in chimato composts Td50 and Td60 with T. diversifolia and maize stalks blending composition (Td/MS) of 50:50 and 60:40. The lower values of carbon reduction observed in Td50 and Td60 is in accordance to stable humus contained in well matured composts which are attributable to improved cation exchange capacity of the soil (Tsutsuki, 2009; Tani, 2009). Carboxyl groups of the organic matter might have increased number of negative charges that increased cation exchange capacity of the soil. Cation exchange capacity of soil in Td50 and Td60 treatments locked up carbon atoms thereby retaining greatest quantity of carbon which was indicated by minimal carbon reduction. Though Td80 and Td100 treatments retained lower carbon atoms than Td50 and Td60 treatments, Td80 and Td100 treatments experienced least carbon losses both by percentage and quantity. The observation is attributed to presence of significant quantities of carbonates in chimato composts Td80 and Td100 which might have been leached down out of the soil, an occurrence likely to cause significant carbon reduction. However, carbon atoms lost through leaching remained in the underground soil, a loss likely to enhance underground soil carbon sequestration rather than emission into the atmosphere. Regression analysis of the carbon losses for second cropping season was developed as shown in Figure 3. Both a third order polynomial and a quadratic equation showed a high negative agreement between initial $T$. diversifolia used in making chimato composts and carbon losses from the soils during the second cropping season $(\mathrm{r}=0.985)$. The regression analysis indicated that greater losses were inevitable in soils supplemented with $\mathrm{Td} 0, \mathrm{Td} 20$ and $\mathrm{Td} 40$. The minimal carbon reductions also suggested that carbon remained almost constant in Td50, Td60, Td80 and Td100 treatments.

\subsection{Impact of T. diversifolia Chimato Composts on Total Kjeldahl Nitrogen on Soil}

In general, result showed increase in total Kjeldahl nitrogen in soil of all chimato compost supplementation treatments. However, high total Kjeldahl nitrogen content was observed in soils of Td50, Td60, Td80 and Td100 treatments during the initial cropping season (Table 2). The initial increase is attributable to richness of the compost due to Tithonia diversifolia as expected because the nitrogen rich chimato composts provided enormous initial nitrogen to the soils (Mlangeni, 2013). Low initial values of TKN were observed in soils of Td0, Td20 and $\mathrm{Td} 40$ treatments in the first cropping season. The low values are attributable to poor quality of composts $\mathrm{Td} 0$, $\mathrm{Td} 20$ and $\mathrm{Td} 40$ that supplied soils with insignificant quantities of nitrogen.

Table 2. Variations of TKN atoms in $5 \mathrm{~kg}$ soils supplemented with chimato composts

\begin{tabular}{lcccccccc}
\hline CC Treatment & Initial TKN in Soil + CC & ${ }^{\mathrm{a}}$ Soil TKN & ${ }^{\mathrm{a}} \mathrm{TKN}$ lost & ${ }^{\mathrm{b}}$ Soil TKN & ${ }^{\mathrm{b}} \mathrm{TKN}$ lost & Mean CC Initial pH & Soil ${ }^{\mathrm{a}} \mathrm{pH}$ & Soil ${ }^{\mathrm{b} H}$ \\
\hline $\mathrm{Td} 0$ & $3.41 \pm 0.02$ & $2.56 \pm 0.04$ & $0.85 \pm 0.02$ & $1.89 \pm 0.04$ & $0.67 \pm 0.01$ & 7.87 & $6.59 \pm 0.05$ & $6.98 \pm 0.05$ \\
$\mathrm{Td} 20$ & $3.69 \pm 0.02$ & $2.45 \pm 0.04$ & $1.24 \pm 0.02$ & $1.77 \pm 0.03$ & $0.68 \pm 0.01$ & 8.64 & $6.63 \pm 0.04$ & $6.89 \pm 0.04$ \\
$\mathrm{Td} 40$ & $4.79 \pm 0.04$ & $3.51 \pm 0.03$ & $1.28 \pm 0.02$ & $3.17 \pm 0.04$ & $0.34 \pm 0.02$ & 9.47 & $7.08 \pm 0.07$ & $7.14 \pm 0.07$ \\
$\mathrm{Td} 50$ & $6.11 \pm 0.04$ & $5.12 \pm 0.04$ & $0.99 \pm 0.01$ & $4.76 \pm 0.03$ & $0.36 \pm 0.03$ & 10.03 & $7.36 \pm 0.07$ & $7.22 \pm 0.07$ \\
$\mathrm{Td} 60$ & $7.35 \pm 0.03$ & $5.56 \pm 0.05$ & $1.79 \pm 0.01$ & $4.82 \pm 0.04$ & $0.74 \pm 0.02$ & 9.99 & $7.33 \pm 0.06$ & $7.20 \pm 0.06$ \\
$\mathrm{Td} 80$ & $8.46 \pm 0.04$ & $4.54 \pm 0.02$ & $3.92 \pm 0.02$ & $2.94 \pm 0.02$ & $1.60 \pm 0.02$ & 10.04 & $7.30 \pm 0.04$ & $7.22 \pm 0.04$ \\
Td100 & $8.90 \pm 0.04$ & $3.46 \pm 0.03$ & $5.44 \pm 0.02$ & $2.61 \pm 0.03$ & $0.85 \pm 0.02$ & 9.26 & $7.29 \pm 0.06$ & $7.21 \pm 0.06$ \\
Control & $0.12 \pm 0.03$ & $0.08 \pm 0.01$ & $0.04 \pm 0.01$ & $0.06 \pm 0.01$ & $0.02 \pm 0.01$ & 4.85 & $6.30 \pm 0.03$ & $5.92 \pm 0.03$ \\
\hline
\end{tabular}

$\mathrm{a}=$ after 1st (Year) cropping season.

$\mathrm{b}=$ after 2nd (Year) cropping season.

After the first cropping season, a reduction with huge margin in soil TKN was observed in Td80 and Td100 treatments as shown in Table 2). Another significant reduction though with smaller margin was also observed in $\mathrm{Td} 50$, and Td60 and an insignificant reduction $(\mathrm{p}<0.025)$ was observed in $\operatorname{Td} 0, \operatorname{Td} 20$ and $\operatorname{Td} 40$ treatments 
(Table 2). The reduction with huge margin in soils of Td80 and Td100 treatments is attributed two effects namely: -1) leaching of water soluble nitrates and ammonium salts because mature composts are characterized as containing high percentage water soluble nitrogen (EPA, 2008; Bernal et al. 1998). Water soluble nitrogen leached out of the top soils and some ammonium volatized (Mlangeni, 2013). -2) plant nutrient uptake- plants used the nitrogen to build its biomass hence the reduction. The significant reduction in TKN observed in soils of Td50 and Td60 treatments were associated to nutrient up-take by plants rather than nitrogen emissions or further decomposition process losses. The composts used in Td50 and Td60 treatments were optimally matured and with less or no nitrogen required further degradation that could emit or volatize significant nitrogen atoms. But most of nitrogen and other water soluble salts were free and available for plant up take. Loss of nitrogen increased $\mathrm{C} / \mathrm{N}$ ratio which caused nitrogen mineralization to be accelerated (Tsutsuki, 2009; Tani, 2009; Gill et al., 2012) and nitrogen was synthetically utilized to build the crop biomass hence depleting the soil nitrogen. Comparison of soil supplemented with chimato composts and those without crops, revealed significant nitrogen losses. Nitrogen reductions in treatments with no plants suggested that nitrogen losses were incurred through other means other than plant uptake only. Since soil nitrogen losses decreased in increasing order of order of percentage of $T$. diversifolia (Table 2), composts in $\mathrm{Td} 0, \mathrm{Td} 20$ and $\mathrm{Td} 40$ treatments might have experienced significant degradation that further generated volatile nitrogen gases that escaped the soils hence the significant reduction. Even though chimato composts $\mathrm{Td} 0, \mathrm{Td} 20$ and $\mathrm{Td} 40$ possessed low initial nitrogen, results have shown that its low initial nitrogen was subjected to a continued gradual degradation after the compost was added to the soil (Gill et al, 2012; EPA, 2008; Wu, 2000). The degradation/digestion had a high probability of either being incomplete or proceeding uncontrollably or both. The scene was likely to produce more potent, high and proactive greenhouse gases, methane and nitrous oxides. As previously discussed elsewhere in this paper, methane is 23 times and nitrous oxide is 296 times worse than carbon dioxide and its emissions into the atmosphere while some of the nitrogen species positively affected soil nitrogen content for being plant usable nitrogen. A few nitrogen species might have lost from the soil through leaching. But all these suggested phenomena decreased soil nitrogen content for the following cropping season. However, soil nitrogen content in almost all treatments except the control was observed much higher than their initil soil nitrogen content.

\subsection{Effects of $p H$ of Chimato Composts on Soil $p H$}

Generally upon supplementing the poor soils with T. diversifolia chimato composts, significant increase in soil $\mathrm{pH}$ was observed $(\mathrm{p}<0.025)$. Td50 treatments recorded highest $\mathrm{pH}$ values $(7.36)$ followed by Td60 (7.33), Td80 (7.30), and $\mathrm{Td} 40$ (7.08) and at the same time $\mathrm{Td} 0$ and $\mathrm{Td} 20$ resulted in low $\mathrm{pH}$ values (6.59 and 6.63 respectively) (table 2). In the following cropping season, insignificant differences were observed in soil pH of Td100 (7.21), Td80 (7.22), Td60 (7.20), Td50 (7.22) and Td40 (7.14) except for $\mathrm{Td} 0$ and $\mathrm{Td} 20$ which showed significant differences $(\mathrm{pH}=6.98$ and $\mathrm{pH}=6.89$ respectively). The observed increase in soil $\mathrm{pH}$ could be attributable to proton $\left(\mathrm{H}^{+}\right)$transfer from acidic soil to composted basic materials whose $\mathrm{pH}$ was high $(\mathrm{pH}=8.9)$. Initial soil $\mathrm{pH}$ of soil was 4.85 and that of the compost materials was 9.93 (Mlangeni, 2013). The difference observed in Td60, Td80 and Td100 might be explained by neutralization reaction of basic carbonates species with cations present in the soil which include hydrogen protons $\left(\mathrm{H}^{+}\right)$. Thus, acid/base neutralization might have occurred since significant amounts of carbonates were expected in Td60, Td80 and Td100 chimato composts which possessed high $\mathrm{pH}$ values. High $\mathrm{pH}$ values in composts are precursor to high concentration of carbonates (Mlangeni, 2013). On the other hand, lower values of $\mathrm{pH}$ in $\mathrm{Td} 0$ and $\mathrm{Td} 20$ chimato composts decreased carbon mineralization process in soils treated with chimato composts Td0 and Td20 confirming findings of Biala (2011) and Gill et al, (2012) that immature composts produce significant amounts of carbonates in the subsequent years, hence the occurrence further increased soil $\mathrm{pH}$. 


\subsection{Impact of pH of Chimato Composts on Soil Carbon Retention}

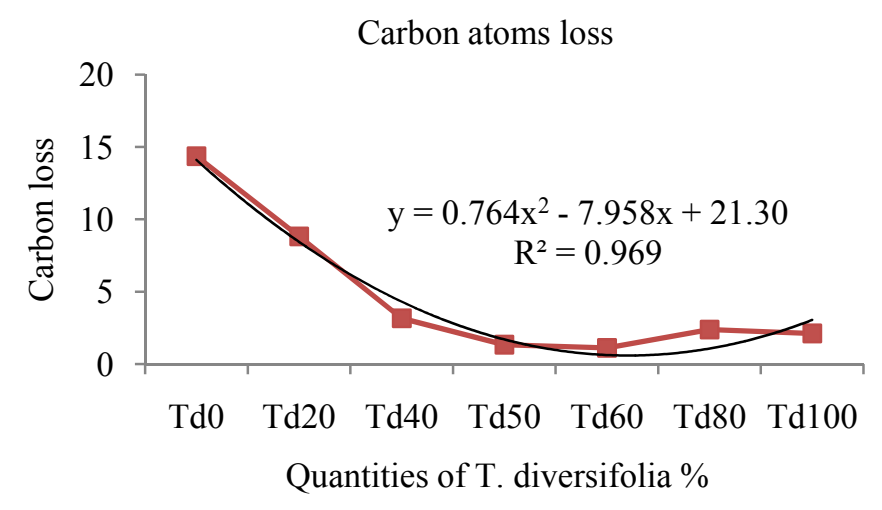

Figure 3. Effect of quantities of T. diversifolia on carbon losses

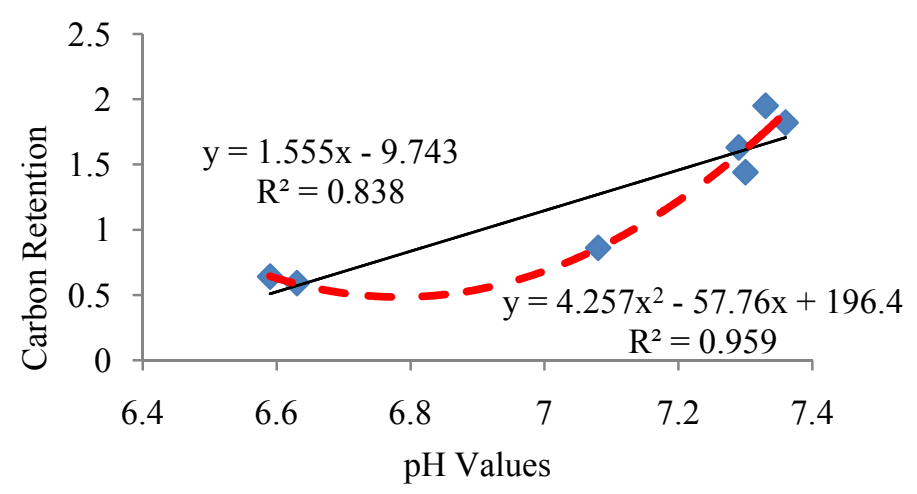

Figure 4. Effect of $\mathrm{pH}$ of chimato composts on soil carbon retention

The results have shown $\mathrm{pH}$ of chimato composts supplemented into the soils significantly affected soil carbon retention and carbon losses (Figure $3 \&$ Figure 4). Three regresion models were run. All regression analyses have shown that soil $\mathrm{pH}$ was negatively related to soil carbon losses and positively related to soil carbon retention $\left(\mathrm{R}^{2} \geq 0.808\right)$ after the first cropping season (Figure $3 \&$ Figure 4$)$. The observation indicated that Td100, Td80, Td60 and Td50 chimato compost possessed significant amounts of carbonates and other inorganic substrates that bound and restricted significant carbon atoms from escaping from the soil hence minimal carbon losses. However, both relationships have shown strong correlation and least carbon emissions may have occurred somewhere around $\mathrm{pH} 6.30$ of Td60 and Td50 treatments whose composts possessed initial high $\mathrm{pH}(\mathrm{pH}>8.3)$ values. Mature and stable composts produced using larger quantities of $T$.diversifolia are reported to possess large quantities of carbonates which can bind cations such as $\mathrm{K}^{+}, \mathrm{Ca}^{2+}$ and $\mathrm{NH}_{4}{ }^{+}$. In addition, chimato composts with $\mathrm{pH}>8.3$ suggests occurrence of carbonates, it further confirms that $\mathrm{Td} 60$ and $\mathrm{Td} 50$ with $\mathrm{pH}=10.03$ and $\mathrm{pH}=9.32$ respectively may have possessed large quanties of carbonates that may have complexed with metal cations and formed metal chelates such as calcium carbonate or potassium carbonates (ASL, 2010; Onwueme \& Sinha, 1991). Such chelates are likely to increase quantity of carbon atoms retained in underground soils thereby reducing soil carbon losses. Therefore, high retention (low carbon loss) could be attributable to such carbonates which is supported by low $\mathrm{pH}$ values of soil. Therefore, chimato composts produced using Tithonia diversifolia/maize stalks blending ratio of greater than $40 \%$ have potential of sequestrating carbon into underground soil through increasing carbon retention as well as reducing of carbon emissions.

\section{Conclusion}

The study results have shown that chimato composts made using higher percentage of $T$. diversifolia have greater potential of diverting atmospheric carbon and lock it up into soil, significantly reducing surface soil carbon and 
its emissions. It has been noted that carbon in soils supplemented with chimato composts produced using blending ratios of TD/MS $>50$ is more stable and more resistant to further degradation than those made using using TD/MS $\leq 40$ which continued to emit carbon into atmosphere. Hence, chimato composts made using blending ratios of TD/MS > 50 significantly reduce soil carbon losses and significantly help mitigate climate change. Therefore, household farmers should be encouraged to supplement their fields with chimato compost prepared by blending $T$. diversifolia to maize stalks with blending ratios of TD/MS $>50$ in order to significantly reduce carbon emissions. Therefore, T. diversifolia chimato composts have great potential in sequestrating carbon by locking up the carbon into underground hence mitigates climate change. Chimato composts made using blending ratios of TD/MS $>50$ also possess high nitrogen content for crop production farmers are expected to welcome its application with minimal resistance. In addition, high $\mathrm{pH}$ of $T$. diversifolia chimato composts potentially affect formation of carbonates which may be retained in the soil for longer period of time. Therefore, application well matured $T$. diversifolia chimato composts should be encouraged among smallholder farmers for soil-building, enhancing soil alkalinity and enhancing soil carbon stability which are essential for soil enrichment as well as sequestrating carbon into underground soil.

\section{Acknowledgments}

I express my profound gratitude to Leadership for Development (Southern and Eastern Africa) (LEAD -SEA) and Natural Resources College (NRC) for the financial support and academic interests in the studies.

\section{References}

Bernal, M., Sanchez-Mondero, M., Paredes, C., \& Roig, A. (1998). Carbon mineralization from organic wastes at different composting stages during their incubation with soil. Agriculture, Ecosystems \& Environment. 69(3), 175-189. http://dx.doi.org/10.1016/S0167-8809(98)00106-6

Biala, J. (2011). The benefits of using compost for mitigating climate change. Department of Environment, Climate Change and Water NSW. DECCW 2011/0171. Retrieved from http://www.environment.nsw.gov.au

Californian Against Waste (CAW). Composting: A Greenhouse Gas Mitigation Measure. Retrieved from http://www.cawrecycles.org/issues/ghg/compost

California Compost Quality Council (CCQC). (2001). Compost maturity index. Nevada City, Canada: California Compost Quality Council. Retrieved from http://www.epa.gov/compost/pubs/ca-index.pdf

US Environmental Protection Agency (EPA). (2008). Municipal Solid Waste Generation, Recycling, and Disposal in the United States: Facts and Figures for 2007. Washington, DC: U.S. Environmental Protection Agency, Office of Solid Waste and Emergency Response. Retrieved from http://www.epa.gov/epawaste/ nonhaz/municipal/pubs/msw

Francou, C., Lineres, M., Derenne, S., Willio-Poitrenaud, M., \& Houot, S. (2008). Influence of green waste, biowaste and paper-cardboard initial ratios on organic matter transformations during composting. Bioresource Technology, 99(18), 8926-8934. http://dx.doi.org/10.1016/j.biortech.2008.04.071

Gill, R. A., Anderson, L.J., Polley, H. W., Johnson, H. B., \& Jackson, R. B. (2006). Potential nitrogen constraints on soil carbon sequestration under low and elevated atmospheric $\mathrm{CO}_{2}$. Ecology, 87(1), 41-52. http://dx.doi.org/10.1890/04-1696

Global Repair (GR). (2013). Greenhouse gas emissions \& aerobic compost facts. Retrieved from http://www.globalrepair.ca/Greenhouse gas emissions.htm

Greater Manchester Waste Disposal Authority (GMWDA). (2009). Climate Change Action Plan 2009-2012. Retrieved from http://www.gmwda.gov.uk

Jeffery, G. H., Bassett, J., Mendham, J., \& Denney, R. C. (1989). Vogel's textbook of quantitative chemical analysis (5th Ed.). New York: Longman.

Mlangeni, A. N. J. T. (2013). Effect of Tithonia Diversifolia on Compost Pile Heat Built-up and Physico-Chemical Quality Parameters of Chimato Compost. Environment and Natural Resources Research, 3(3) 63-70. http://dx.doi.org/10.5539/enrr.v3n3p63

Olabode, O. S., Ogunyeni, S., Akanbi, W. B., Adesina, G. O., \& Babajide, P. A. (2007). Evaluation of Tithonia Diversifolia (Hemsl): A gray for soil improvement. World Journal of Agricultural Sciences, 3(4), 503-507.

Prochnow, L. I., Kiehl, J. C., Pismel, F. S., \& Corrente, J. E. (1995). Controlling ammonia losses during manure composting with the addition of phosphogypsum and simple superphosphate. Scientia Agricola, 52(2). http://dx.doi.org/10.1590/S0103-90161995000200024 
Swift, M. J., Heal, O. W., \& Anderson, J. M. (1979). Decomposition in Terrestrial Ecosystem. Oxford: Blackwell Scientific Publication.

Tani, M. (2009). Analysis of Total Carbon and Nitrogen in Composts and Manures. Obihiro: Obihiro University of Agriculture and Veterinary Medicine.

Tsutsuki, K. (2009). Fundamentals in compost preparation and Utilization. Obihiro: Obihiro University of Agriculture and Veterinary Medicine.

United States Composting Council (USCC). (2008). USCC factsheet: composting, Global Climate Change and Carbon Trading. The United States Composting Council. Retrieved from http://www.compostingcouncil.org

Washington State University (WSU). (2010). Fundamentals of composting: Why compost, material and methods to ensure quality compost (Whatcom Extension Research Report). Washington: Washington State University.

Wu, L., Ma, L. Q., \& Martinez, G. A. (2000). Comparison of Methods for Evaluating Stability and Maturity of Biosolids Compost. Journal of Environmental Quality, 29(2), 424-429. http://dx.doi.org/10.2134/jeq2000.292424x

\section{Copyrights}

Copyright for this article is retained by the author(s), with first publication rights granted to the journal.

This is an open-access article distributed under the terms and conditions of the Creative Commons Attribution license (http://creativecommons.org/licenses/by/3.0/). 